\title{
Deep structure beneath the southwestern section of the Longmenshan fault zone and seimogenetic context of the 4.20 Lushan $M_{\mathrm{S}}$ 7.0 earthquake
}

\author{
ZHAN Yan ${ }^{1}$, ZHAO GuoZe ${ }^{1 *}$, UNSWORTH Martyn ${ }^{2}$, WANG LiFeng ${ }^{1}$, CHEN XiaoBin ${ }^{1}$, \\ LI Tao ${ }^{1}$, XIAO QiBin ${ }^{1}$, WANG JiJun ${ }^{1}$, TANG Ji ${ }^{1}$, CAI JunTao ${ }^{1}$ \& WANG YanZhao ${ }^{1}$ \\ ${ }^{1}$ State Key Laboratory of Earthquake Dynamics, Institute of Geology, China Earthquake Administration, Beijing 100029, China; \\ ${ }^{2}$ Department of Earth and Atmospheric Sciences, University of Alberta, Edmonton T6G 2E3, Canada
}

Received June 9, 2013; accepted July 5, 2013; published online August 13, 2013

\begin{abstract}
Magnetotelluric measurements were carried out along two profiles across the middle and southwestern sections of the Longmenshan fault zone (LMSf) from 2009 to 2011, after the 2008 Wenchuan $M_{\mathrm{W}} 7.9$ earthquake. The former profile crosses the Wenchuan event epicenter and the latter one crosses 2013 Lushan $M_{\mathrm{S}} 7.0$ event epicenter. The data were analyzed using advanced processing techniques, including phase tensor and two-dimensional inversion methods, in order to obtain reliable 2-D profiles of the electrical structure in the vicinity of the two earthquakes. A comparison of the two profiles indicates both similarities and differences in the deep crustal structure of the LMSf. West of the southwestern section, a crustal high conductivity layer (HCL) is present at about $10 \mathrm{~km}$ depth below the Songpan-Garzê block; this is about $10 \mathrm{~km}$ shallower than that under the middle section of the LMSf. A high resistivity body (HRB) is observed beneath the southwestern section, extending from the near surface to the top of upper mantle. It has a smaller size than the HRB observed below the middle section. In the middle section, there is a local area of decreased resistivity within the HRB but there is absence of this area. The 2013 Lushan earthquake occurred close to the eastern boundary of HRB and the Shuangshi-Dachuan fault, of which the seismogenic context has both common and different features in comparison with the 2008 Wenchuan event. On a large scale, the 2013 Lushan earthquake is associated with the HCL and deformation in the crust including HCL of the eastern Tibetan Plateau. In order to assess seismic risk, it is important to consider both the stress state and the detailed crustal structure in different parts of the LMSf.
\end{abstract}

Longmenshan fault, Lushan earthquake, deep structure, seismogenetic context

Citation: Zhan Y, Zhao G Z, Unsworth M, et al. Deep structure beneath the southwestern section of the Longmenshan fault zone and seimogenetic context of the 4.20 Lushan $M_{\mathrm{S}} 7.0$ earthquake. Chin Sci Bull, 2013, 58: 3467-3474, doi: 10.1007/s11434-013-6013-x

On 20 April, 2013, a major earthquake, with a magnitude of $M_{\mathrm{S}} 7.0$ recorded by China Earthquake Administration, struck Lushan in Sichuan Province. It was caused by the failure of the southwestern segment of the Longmenshan fault zone (LMSf). Almost five years ago, on 20 May, 2008, rupture of the middle section of the same fault zone spawned the devastating $M_{\mathrm{W}} 7.9$ Wenchuan earthquake. The source of the Wenchuan event was at the depth of 14-19 km. It ruptured the Beichuan and Pengguan faults, with vertical and hori-

*Corresponding author (email: zhaogz@ies.ac.cn) zontal displacements up to 6.5 and $4.9 \mathrm{~m}$ [1], and 240-300$\mathrm{km}$-long and 90-km-long surface rupture zones, respectively [2,3]. The rupture was especially large near the town of Yingxu. However, the rupture and aftershocks of this huge earthquake did not extend to the southwest, where the 2013 Lushan earthquake took place.

After the 2008 Wenchuan earthquake, two issues have been highly debated. One is the question of why the 2008 earthquake occurred at the LMSf, a region that was previously considered to be stable. The other is why the rupture and aftershocks of this event did not extend to the south- 
western segment of the fault zone. GPS measurements show little motion $(<2 \mathrm{~mm} / \mathrm{a})$ [4] across the LMSf before the 2008 event, much less than that on the neighboring YushuXianshuihe fault (YXf), East Kunlun fault (EKLf) and Anninghe-Zemuhe fault [4,5] (Figure 1). There was also a long-term seismically quiet period along the LMSf, with no $M>4$ quakes occurring in 7 years [6], implying much lower seismicity relative to other active faults. Some studies suggest that the middle and southwestern segments of the LMSf might be two independent units [7], and thus the Wenchuan event did not affect the southwestern section. The seismic risk of this was also controversial prior to the 2013 event [8-10]. Some predicted that the southwestern segment of the LMSf would generate another major earthquake [9], while others suggested that such an event would occur around Kangding, where the LMSf and YXf meet, away from the southwestern segment of the LMSf [10].

Two additional questions are: (1) was the 2013 Lushan event an aftershock of the 2008 Wenchuan great earthquake or an independent main shock [11], and (2) was this earthquake triggered by the Wenchuan event [12]? It now seems clear that both events are related, but they have several important differences. Both took place along the LMSf, Wenchuan at the middle section and Lushan at the southwestern section. Their aftershock areas are $45 \mathrm{~km}$ apart [11]. In the middle section, from west to east, are the subparallel Wenchuan-Maowen (WMf), Beichuan (BCf) and Pengguan (PGf) faults, dominated by west-dipping thrust. The BCf and PGf ruptured during the 2008 Wenchuan event [13].

The southwestern section consists of three subparallel faults: the Gengda-Longlong fault (GLf), Wulong fault (WLf), and Shuangshi-Dachuan fault (SHDf). The GLf

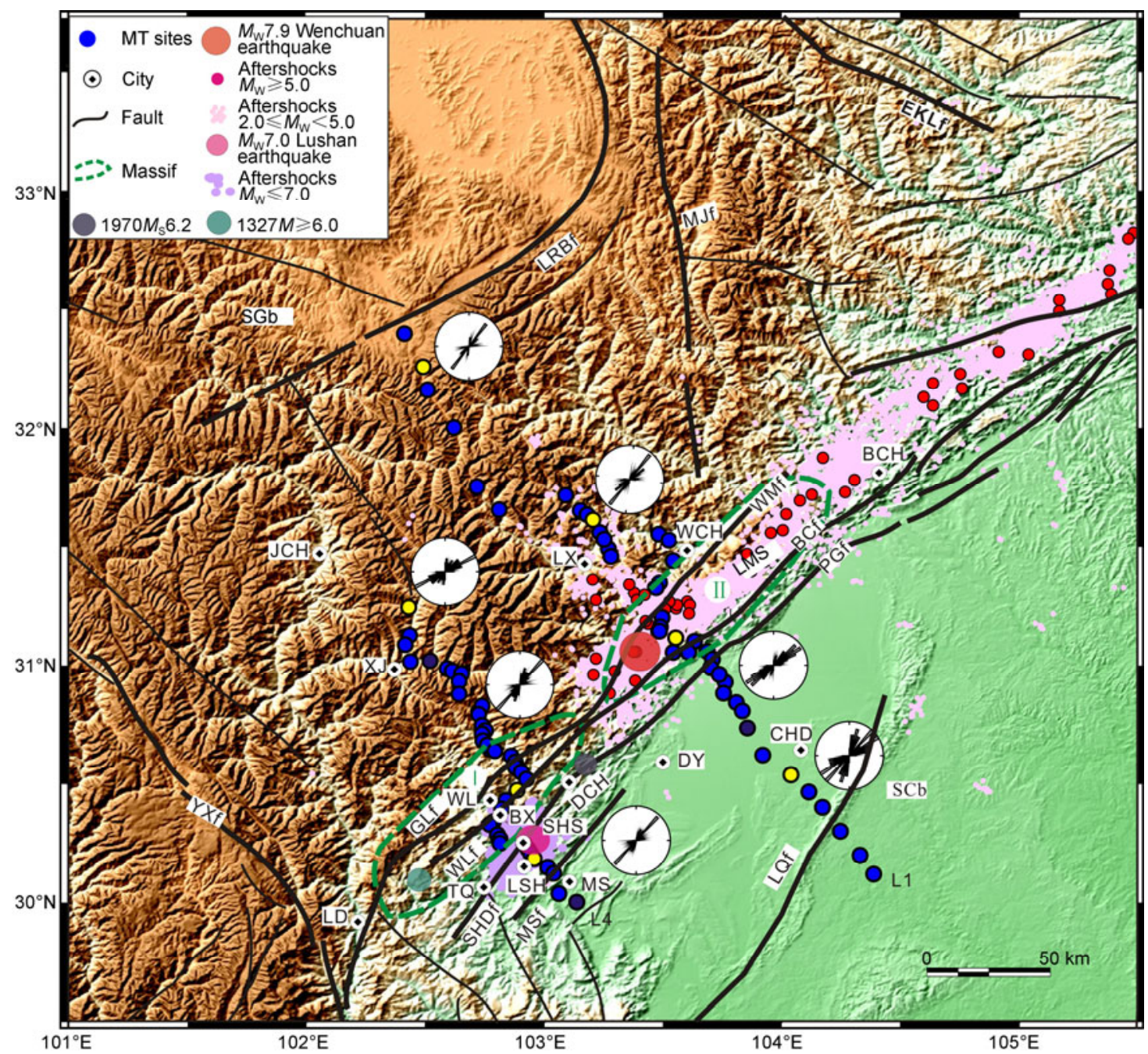

Figure 1 Map showing structure of the southwestern segment of the Longmenshan fault and MT profiles and sites (blue circles). Fault names: LMS, Longmenshan fault; GLf, Gengda-Longdong fault; WLf, Wulong fault; SHDf, Shuangshi-Dachuan fault; MSf, Mingshan fault; WMf, Wenchuan-Maoxian fault; BCf, Beichuan fault; YXf, Yushu-Xianshuihe fault; EKLf, East Kunlun fault; LRBf, Longriba fault; MJf, Mingjiang fault; LQf, Longquan fault. Block names: SGb, Songpan-Garzê black; SCb, Sichuan basin. Place names: CHD, Chengdu; BCH, Beichuan; WL, Wulong; BX, Baoxing; TQ, Tianquan; SHS, Shuangshi; DCH, Dachuan; LSH, Lushan; MS, Mingshan; DY, Dayi; LD, Luding; XJ, Xiaojin; LX, Lixian; JCH, Jinchuan. Massif belts: I Baoxing massif; II, Penggucan massif [13]. Rose diagrams show electric strike. Relocation of main shock and aftershock sequences of $M_{\mathrm{W}} 7.9$ Wenchuan earthquake [23], Relocation of main shock and aftershock sequences of $M_{\mathrm{S}} 7.0$ Sichuan Lushan earthquake [24]. 
extends to the northeast and joins the WMf. The WLf also stretches northeast and connects to the BCf. The SHDf likely meets the PGf in the northeast. Close to the border of Tianquan, the SHDf can be divided into northern and southern parts. The southern part is a west-dipping thrust fault and it is truncated by the NW-trending E'bian fault. The northern part, also a west-dipping thrust, connects to the PGf [7,14]. East of the SHDf is the Mingshan fault (MSf), which is a right-slip thrust fault [7].

Two massif belts are exposed on the LMSf: one is the Pengguan massif, which in the middle section, roughly around the BCf and west of it, the other is the Baoxing massif in the southwestern section [7,15], west of the SHDf. The epicenter of the 2008 Wenchuan event is located near the southwestern end of the Pengguan massif, and the 2013 Lushan event epicenter is situated east of the Baoxing massif [15] (Figure 1).

For both the 2008 and 2013 earthquakes, the details of earthquake occurrence and rupture depend on the structure and rheology of crust and lithospheric mantle beneath the LMSf and adjacent areas [16,17]. The LMSf lies on the southeastern boundary of the Songpan-Garzê block (SGb) of the eastern Tibetan Plateau. Since the Cenozoic, the plateau has been pushed northward by the Indian plate, as it converges with Asia [18], and this has resulted in extrusion of the SGb to the east and southeast, with dominantly horizontal motion [19,20]. Such motion is obstructed by the LMSf and the stable Sichuan basin ( $\mathrm{SCb}$ ) in the southeast, resulting in high seismicity along the eastern margin of the Tibetan Plateau [21]. Interestingly, both the middle and southwestern segments of the LMSf had relatively low earthquake activity and slip rates before 2008 [5,22]. Even before the 2013 Lushan event, only two major $(M \geqslant 6)$ earthquakes were recorded for the southwestern segment until now: the M6.0 event between Baoxing and Kongding on 12 June, 1941 and the M6.2 Dayi earthquake on 24 February, 1970. No events exceeding M6.5 have been documented in the recorded history of this region [9]. In this study, we present two magnetotelluric (MT) sounding profiles that cross the Wenchuan and Lushan earthquake areas (Figure 1). MT measurements provide information about the electrical structure of the crust and upper mantle, and therefore they can be used to understand crustal composition and porosity. Our purpose is to study the structure of the deep crust and upper mantle structure beneath the southwestern segment of the LMSf in order to address the seismogenenic context of the 2013 Lushan event. The data are also useful for addressing some of the above questions about the tectonics and seismicity of this region.

\section{Analysis of MT data and 2D electric structure}

In 2009, MT data were measured along two profiles, with one profile crossing the middle segment of the LMSf where the Wenchuan earthquake occurred and the other crossing southwestern segment where the Lushan earthquake would occur in 2013 (profiles L1 and L4, respectively; Figure 1). Repeated measurements and new measurements at additional sites were conducted on these profiles in 2010 and 2011 to ensure that the data quality was not affected by construction activities after the 2008 earthquake and to obtain data from sites that were difficult to access in 2009. Profile L1, crossing the Wenchuan earthquake area, is 400 $\mathrm{km}$ long and has 40 sites, with an average spacing of 10.3 $\mathrm{km}$ and a mean spacing $4 \mathrm{~km}$ in the vicinity of the earthquake epicenter. On the 154-km-long profile L4 that crosses the Lushan earthquake area, there are 40 sites, with average spacing $3.9 \mathrm{~km}$. Data were collected using the V5-2000 MT instrument system made in Canada, and the data were collected over frequencies of 300-0.001 Hz. Several techniques were employed, including the remote reference MT method for measurement and robust methods for data processing, including apparent resistivity and impedance phase, in order to obtain high-quality MT data [17].

We have analyzed the MT data using the phase tensor method [25-27]. The results show that the skewness is less than 0.3 in the primary frequency bands for most sites, suggesting a dominantly 2D subsurface structure. The electric strike is in the NE direction, largely consistent with the trend of the LMSf (Figure 1). Using the apparent resistivity and phase data of the two profiles, 2D inversion was carried out using the standard NLCG method [28]. A static correction was applied to those sites that were likely subject to static shifts $[29,30]$. The $2 \mathrm{D}$ inversion was carried out multiple times with the widely-used variable Tau and the L-curve method, in order to analyze the tradeoff between model roughness and data fit and to account for data uncertainties [17]. The results show that Tau=10 appears at the corner of the L-curve for both the profiles, and that at this point, the data fitting errors are 1.68 and 2.35 for profiles L1 and L4, respectively, suggesting a good fit between the model and data. Thus, the final models of electric structure for the two profiles are optimal and acceptable (Figure 2).

\section{Deep structure beneath the southwestern segment of the LMSf and adjacent areas}

We have presented the deep structure beneath the middle segment of the LMSf and Wenchuan earthquake area in a previous article [17]. It can be summarized as follows: A high-conductivity layer (HCL) is present at a depth of 20 $\mathrm{km}$, below the resistive upper crust of the SGb west of the LMSf. At the LMSf, a high-resistivity body (HRB) extends from the near-surface to the upper mantle and includes the area from close to the PGf fault to $25 \mathrm{~km}$ west of the WMf. This area, with a width of $70 \mathrm{~km}$, is roughly consistent with the "rupturing unit" [4] or "transitional zone" [31] discussed in previous studies. Continuing to the east, the HRB links to 
(a)
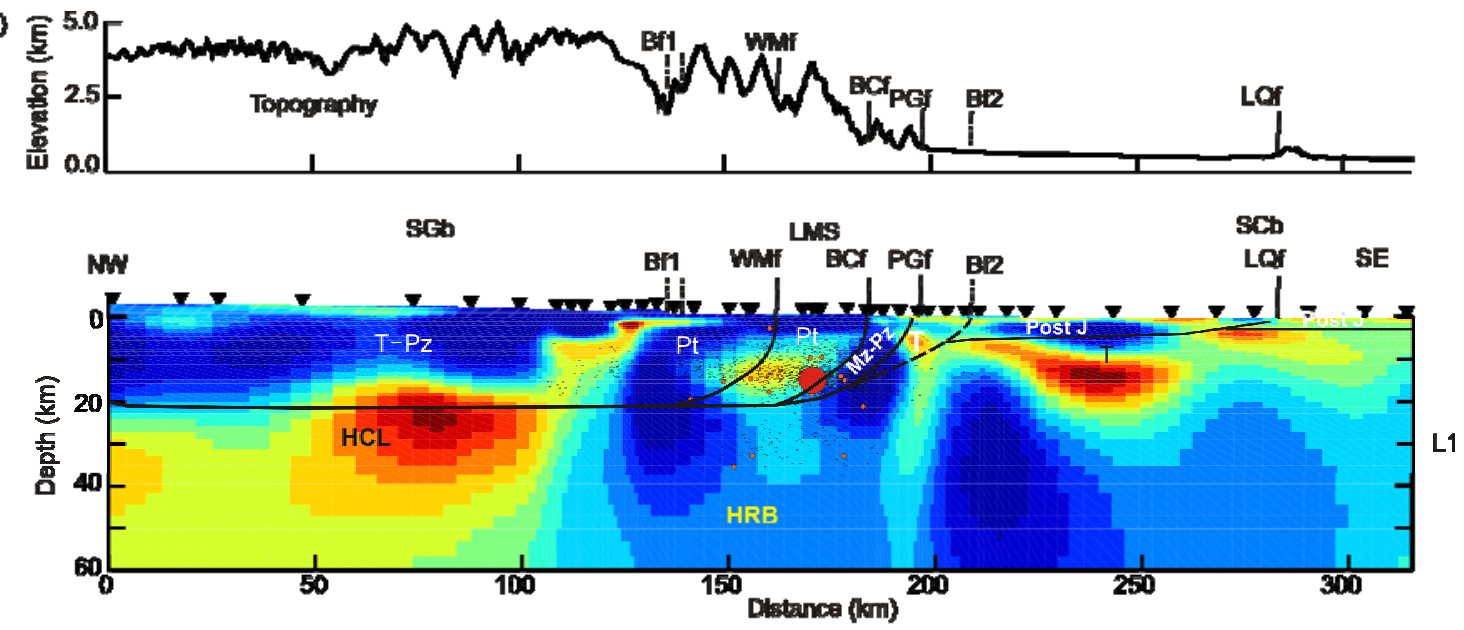

(b)

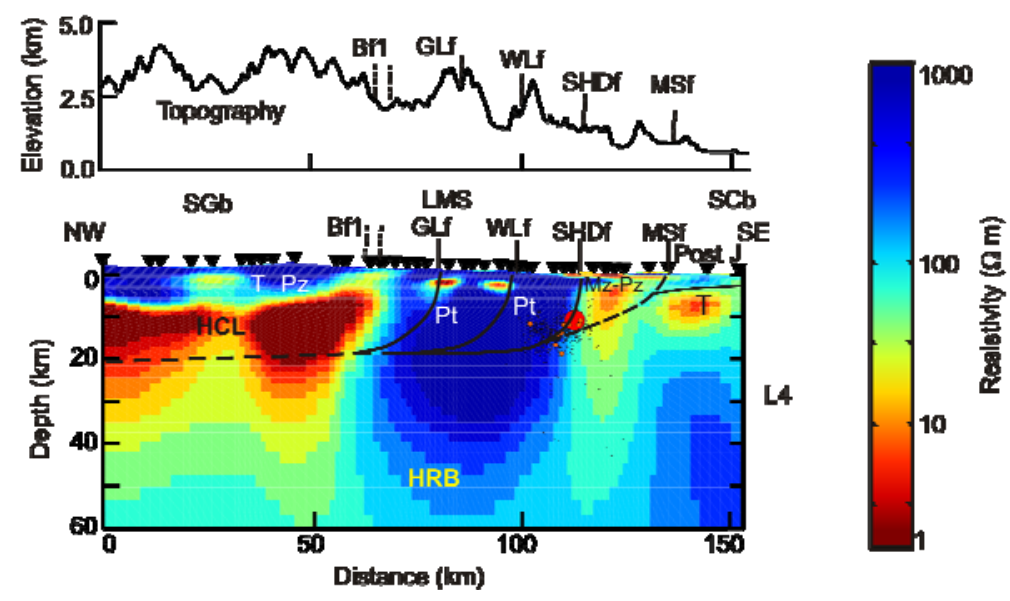

Figure 2 Two-dimensional electric structure along profiles L1 (a) and L4 (b). HCL, high conductivity layer; HRB, high resistivity body. Fault names are the same as in Figure 1.

the resistive basement of the Sichuan basin at a depth of about $10 \mathrm{~km}$. There is no evidence that the HCL layer in the $\mathrm{SGb}$ is connected to the inside of the HRB. Within the LMSf, the Wenchuan earthquake source region appears as a local area of decreased resistivity (profile L1 in Figure 2).

A comparison between the profiles across the middle segment and southwestern segment (profile L4 in Figure 1) shows that there are both similarities and differences in the deep electrical structure of the two regions. On the west of the southwestern segment, a $\sim 10-\mathrm{km}$-thick resistive layer is observed in the shallow subsurface, close to the southeastern corner of the SGb and close to the intersection of the LMSf and YXf. However, its thickness is less than that observed on the profile across the middle segment. Below this layer, a HCL is observed in crust. The lowest frequency used in the MT survey was $0.001 \mathrm{~Hz}$, which is insufficient to constrain the lower boundary of this layer.

Near the southwestern segment of the LMSf, a HRB that extends from the near-surface to the upper mantle is observed. It is about $45 \mathrm{~km}$ wide and is found from near the SHDf to $10-15 \mathrm{~km}$ west of the GLf. However, there is also no HCL within this HRB connecting to the HCL crust in the west similar to middle segment. The difference is in that there is no a local area of decreased resistivity, as observed at the middle segment of the LMSf. To the east, the gap between the HRB and resistive basement of the $\mathrm{SCb}$ lies between the SHDf and MSf, and it is much wider than that on profile L1. In addition, a lower resistivity layer about $10 \mathrm{~km}$ thick is found near the surface in the SCb. This is likely associated with Mesozoic and Cenozoic sediments of the basin.

Along the southwestern segment of the LMSf, the westdipping GLf and WLf penetrate the HRB at a high angle in the shallow subsurface and become more horizontal at depth. These appear to link with the HCL observed in the west (Figure 2). The SHDf also dips west, close to the eastern boundary of the HRB at depth. Previous studies suggested that the SHDf is the seismogenic fault of the main shock of the 2013 Lushan earthquake and that most aftershocks are located close to the SHDf [11]. This event has also been argued to have been associated with a blind thrust fault because no coseismic rupture was found on the surface [12]. The existence of the MSf close to the eastern boundary of the HRB is likely one of the reasons for the bigger MSf offset from the HRB than observed on the middle segment of the LMSf. 


\section{Deep structure beneath the Lushan earth- quake area}

The 2013 Lushan earthqake, measured as $M_{\mathrm{S}} 7.0$ and $M_{\mathrm{W}}$ 6.6-6.7, occurred at Lushan County $\left(30.284^{\circ} \mathrm{N}, 102.956^{\circ} \mathrm{E}\right)$. The earthquake had a focal depth of 12.3-19 km, and it ruptured a fault striking $\mathrm{N} 30^{\circ}-40^{\circ} \mathrm{E}$ and dipping west at $33^{\circ}-34^{\circ}[11,32-34]$. Most of its aftershocks are located in an elliptical area southwest of the epicenter of the main shock with a 45-km-long NE-trending long axis and 20-km-long NW-directed short axis [11]. In contrast, the aftershocks of the 2008 Wenchuan event are distributed northeast of the main shock. Thus, there is a $45 \mathrm{~km}$ spacing between both the main shocks and aftershock distributions of the two earthquakes [11]. Field investigations have not identified visible rupture zones on the surface produced by the Lushan quake, and its aftershocks exhibit a plane-shaped distribution pattern on a vertical profile though the fault [12].

The source of the Lushan earthquake is adjacent to the eastern boundary of the HRB observed below the LMSf and SHDf (Figure 2), and its aftershocks are found close to the SHDf, with little relation with the WLf and MSf. The HRB beneath the Lushan earthquake is relatively continuous, but it has a smaller size than the HRB associated with the Wenchuan event. In contrast to the Wenchuan seismic source region, no local area of low-resisitivity is found within the HRB below the Lushan quake. It is unclear whether the low-resitivity zone is linked with the occurrence of the earthquake. As no repeated MT measurements were made on profile L4 after the Lushan event, it is impossible to determine whether a local area of decreased resitivity may have appeared following the Lushan earthquake. Similarly, profile L1 was only measured following the 2008 earthquake and thus, it is unknown whether the low-resitivity area on this profile was present prior to the earthquake.

If the local area of decreased resistivity within the HRB on profile L1 is related to the 2008 earthquake rupture, it is interesting to consider the causative mechanism, as this may provide information about the environment in which earthquakes are generated within the LMSf. One possibility is that an earthquake may cause rocks to fracture in the vicinity of the hypocenter, resulting in increased porosity or increased connection between existing cracks in the rocks. The fluid volume and/or crack connection would increase and rock resistivity would decrease. Thus, it is possible that the low resistivity feature within the HRB was produced by the earthquake.

\section{Discussion}

\subsection{HCL and crustal deformation}

On the basis of the electric structure derived from MT profiles crossing the LMSf, in conjunction with geologic and other geophysical studies [4,5,7,13,15-17,20,22,31,35-45], we have suggested that the HCL in the crust of the SGb of the eastern Tibetan Plateau is a layer of low viscosity that is susceptible to deformation or flow, commonly called "channel flow" [16,17,31,35-43]. The existence of this layer is of great significance for studies of the deformation and dynamics of the eastern Tibetan Plateau.

As the HCL is mechanically weak, shear and dilation can occur within this layer as stress is applied, leading to decoupling between upper and lower crust and/or crustal thickening. This may explain why the crust of the SGb is thicker than the SCb by some $20 \mathrm{~km}$ [17]. Furthermore, it has been inferred that the HCL and upper crust of the block are moving around the LMSf and SCb, with motion southsoutheastward along the southwestern segment and northeastward at the northeastern segment of the LMSf, as well as the southeastward movement normal to the middle segment of the LMSf $[5,22,44]$. In the middle segment, flow is inferred to move southeast together with the SGb, but the material in the HCL is obstructed by the rigid HRB of the LMS and SCb, i.e. the conductive, low viscosity mid-crust is unable to intrude into the LMS. The interaction between the weak crust and rigid block are suggested to decrease the horizontal displacement of the upper crust of the SGb $[4,5,22]$, and as flow is dilated along this boundary, it may cause the block to rise rapidly, producing the steep relief between the block and SCb [17].

As the SGb moves around the LMS, crustal motion of the $\mathrm{SGb}$ relative to the LMSf segment has a considerable oblique component on both southwestern and northeastern segments, i.e. more pronounced shear. This may explain why the HCL of the southwestern segment is shallower and has a smaller resistivity value than observed for the middle segment of the LMSf (Figure 2).

Figure 3 shows the deep electrical structure on profile L4 which crosses the Lushan seismic area on the LMSf, as well as a conceptual model of dynamics for this region. As the $\mathrm{SGb}$ moves to southeast as a whole, non-uniform deformation is inferred to occur at different depths in the upper crust as well as in HCL. This may lead to shear deformation within the crust, and decoupling between the upper and lower crust. The LMSf, as a HRB from the near-surface downward to upper mantle, and the neighboring $\mathrm{SCb}$ in the east, are interpreted to be composed of dry, strong crust, which obstructs the southeastward motion of the SGb [4].

As the southeast-directed compression of the SGb crust and HCL is hampered by the HRB, the upper crust in the contact zone between the SGb and LMSf may undergo cracking and deformation. This may cause an increase in rock porosity and water content (marked by $\mathrm{W}$ in Figure 3). Thus, this area has a low resistivity, and this may be indicative of the existence of hidden faults or weak, fractured crust (Bf1).

\subsection{Deep seismogenic context of the Lushan earthquake}

Both the 2013 Lushan and 2008 Wenchuan earthquakes 


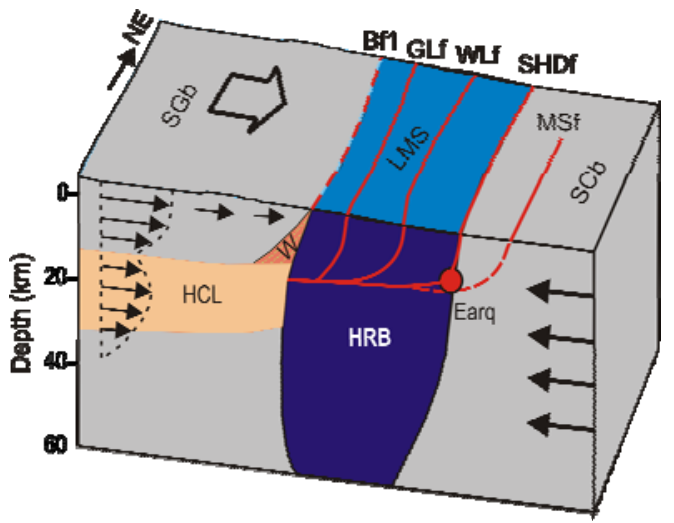

Figure 3 Carton showing deep context of the 2013 Lushan $M_{\mathrm{S}} 7.0$ earthquake on the southwestern segment of the LMSf. Big arrow on the top indicates southeastward motion of the Songpan-Garzê block (SGb), arrows on the left side denote non-uniform movements at varied depths in HCL and resistive upper crust, arrows on the right side show the obstruction of the Sichuan basin ( $\mathrm{SCb}$ ), W means water-bearing broken rock due to shear in upper crust corresponding to hidden fault Bf1, Earq is location of source of Lushan earthquake. Fault names are the same as in Figure 1.

occurred on the LMSf, with the SGb in the west and SCb in the east (Figure 3). They each have distinct deep structures and seismogenic contexts. The upper crust of the SGb and its HCL moves to the southeast. It is obstructed by the NEtrending LMSf and SCb and is deflected along the LMSf, resulting in a T-shaped flow pattern. Before the earthquakes, we suggest that such a T-shaped pattern acted to stabilize the LMSf, leading to very low displacement rates and a long seismically quiet period [6,9]. However, stress continued to accumulate, and once it exceeded the rock strength, different parts of the fault ruptured as large earthquakes.

It should be noted that the crustal motion previously mentioned and its compression on the LMSf are not uniform along the fault. Due to the motion of the SGb around the LMS and $\mathrm{SCb}$, the rate of crustal motion relative to the LMS varies in different sections of the LMSf. The middle segment represents the center of the T-shaped flow pattern, where there is the greatest thrusting. Consequently, this segment is most likely subject to the largest compressive stress and may be more prone to large earthquakes, such as the 2008 Wenchuan event. The southwestern segment of the LMSf, where a HRB contacts the $\mathrm{SCb}$, also experiences southeast-directed compression, as evidenced by the thrusttype Lushan event in 2013 [12]. However, it is inferred that the compressive stress is less than in the middle segment, as flow is oblique to the boundary and this region is composed of many faults.

In the middle segment of the LMSf, a local low-resistivity area is present in the HRB (profile L1, Figure 2), and the main shock and most aftershocks of the Wenchuan event are located within this low-resistivity area and its vicinity. Along the southwestern segment of the LMSf, no such low-resistivity area exists in the HRB (profile L4, Figure 2), and the main shock and aftershocks took place at east mar- gin of the HRB. This may account for plane-shaped distribution of aftershocks of the Lushan event on the vertical profile through the fault [12].

There are several important differences in the crustal structure of the Lushan and Wenchuan earthquake areas. West of the Lushan earthquake area, the HCL in the crust is at a depth of $10 \mathrm{~km}$, whereas this feature is at a depth of about $20 \mathrm{~km}$ west of the Wenchuan earthquake area. The HRB beneath Lushan is smaller than that below Wenchuan. In addition, there is a gap between the HRB and the resistive $\mathrm{SCb}$, which is inferred to represent mechanically weak rock. The gap is wider below Lushan than it is beneath Wenchuan. Furthermore, the two earthquakes took place within different crustal massifs (Baoxing and Pengguan massif). All of these factors may play a role in controlling earthquake magnitude. We suggest that the differences in crustal structure below the two profiles may explain why the magnitude of the Lushan earthquake $\left(M_{\mathrm{S}} 7.0\right)$ is smaller than that of the Wenchuan event $\left(M_{\mathrm{W}} 7.9\right)$.

Both events are associated with the motion of the SGb and its obstruction by the LMSf and $\mathrm{SCb}$, indicative of a similar tectonic setting. However, their sources are located within different deep crustal structures with distinct physical properties. Thus, we conclude that they are two independent seismic events, rather than events that have a main shock-aftershock relationship [11]. Even if the Lushan earthquake were triggered by the Wenchuan event [12], we believe that the Wenchuan event did not play an important role in the Lushan event. Instead, the occurrence of the Lushan earthquake appears to be controlled by the local crustal structure and stress state in this part of the LMSf.

\subsection{Relationship between deep structure and seismic risk}

Although the occurrence of earthquakes is related to stress build-up along faults in crust, the stress state is not the only factor that determines the seismic risk. Other factors, such as deep crustal structure, tectonic setting, and the properties of the rock material in the fault zone should be taken into consideration. In the eastern Tibetan Plateau, the interaction between the SGb and LMSf is a major factor that can trigger large earthquakes. This will continue to contribute to seismic risk along the entire LMSf in the future. The 2008 Wenchuan and 2013 Lushan events have released some strain energy in the middle and southwestern segments of the LMSf, and therefore it is likely that it will take a long time to accumulate sufficient stress for a future large earthquake. However, there is a space between the two earthquake areas that is about $45 \mathrm{~km}$ long, in which there were almost no aftershocks of the two events. From outcrops, the two massif areas do not connect in the shallow subsurface (Figure 1), but it is unclear whether the two areas are linked at depth. This should be investigated further through geophysical studies. If there is no link between the areas, the 
upper crust in this space may be different from that in the north and south. In this case, the seismic risk of this area may be different, and this should be considered in seismic hazard assessments of the southern LMSf.

Along the southwestern segment of the LMSf, where the YXf and Anninghe faults meet, GPS measurements indicate that the crust of the SGb moves toward the southeast relative to the LMSf. In this area, the T-shaped flow pattern previously mentioned does not exist, and strike-slip faulting is the dominant deformation style that accommodates southeastward motion of the SGb. The complicated crustal structure and possible channel flow at depth, as well as the lack of documented historical earthquakes with magnitudes greater than 6.5 , suggest that this region has a high potential of major earthquakes in the future [9]. The northeast end of the LMSf, where the LMSf, EKLf and West Qingling fault zone merge, has a similar tectonic setting and is also dominated by strike-slip faulting. The seismic hazard in this region depends on stress accumulation on active faults, as well as the deep crustal structure and its seismogenic context. These are factors that need to be explored further in order to assess seismic risk for this region.

This work was supported by the National Basic Research Program of China (2008CB425702-2), the National Natural Science Foundation of China (41074046 and 41074047), the Director Foundation of Institute of Geology, China Earthquake Administration (IGCEA1013), and the Investigation Project for Wenchuan Earthquake of China Earthquake Administration. The authors thank the 711 Electric Team of Geophysical Exploration Company, Jianghan Petroleum Administration for their assistance in data collection. We also thank Zhang Peizhen and three referees for their invaluable suggestions and Claire Currie for her helpful suggestions.

$1 \mathrm{Xu} \mathrm{X,} \mathrm{Wen} \mathrm{X,} \mathrm{Yu} \mathrm{G,} \mathrm{et} \mathrm{al.} \mathrm{Coseismic} \mathrm{reverse} \mathrm{and} \mathrm{oblique-slip} \mathrm{sur-}$ face faulting generated by the $2008 M_{\mathrm{W}} 7.9$ Wenchuan earthquake, China. Geology, 2009, 37: 515-518

2 Huang Y, Wu J P, Zhang T Z, et a1. Relocation of the M8.0 Wenchuan earthquake and its aftershock sequence. Sci China Ser D-Earth Sci, 2008, 51: 1703-1711

3 Zhang Y, Feng W P, Xu L S, et a1. Spatiotemporal rupture process of the 2008 great Wenchuan earthquake. Sci China Ser D-Earth Sci, 2009, 52: 145-154

4 Zhang P Z, Wen X Z, Xu X W, et al. Tectonic model of the great Wenchuan earthquake of May 12, 2008, Sichuan, China. Chin Sci Bull, 2009, 54: 944-953

5 Shen Z K, Lu J, Wang M, et al. Contemporary crustal deformation around the southeast borderland of the Tibetan Plateau. J Geophys Res, 2005, 110: 1-17

6 Zhang Y X, Wang H M, Wang L Y, et al. Northeast Area Earthquake Prediction Research in 2009. See: China Earthquake Networks Center, China Earthquake Prediction Research. Beijing: Seismological Press, 2008. 326-366

7 Zhang Y Q, Li H L. Southwest section of the Longmen Shan fault zone Late Quaternary investigation and analysis technique (in Chinese). Quat Res, 2010, 30: 699-710

8 Zhang H P, Zhang P Z, Kirby E, et al. Along-strike topographic variation of the Longmen Shan and its significance for landscape evolution along the eastern Tibetan Plateau. J Asian Earth Sci, 2011, 40: 855-864

9 Yi G X, Wen X Z, Xin H, et al. The southern section of Longmen Shan fault zone stress state and earthquake hazard studies (in Chi- nese). Chin J Geophys, 2013, 56: 1112-1120

10 Qin X H, Chen Q C, Tan C X, et al. Longmen Shan fault zone southwest section of the present-day state of stress and seismic hazard analysis (in Chinese). Rock Mech Eng, 2013, 32: 2870-2876

11 Liu J, Yi G X, Zhang Z W, et al. 2013 April 20 M7.0 earthquake in Sichuan Lushan introduction (in Chinese). Chin J Geophys, 2013, 56: 1404-1407

$12 \mathrm{Xu} \mathrm{X} \mathrm{W,} \mathrm{Han} \mathrm{Z} \mathrm{J,} \mathrm{Li} \mathrm{C} \mathrm{Y,} \mathrm{et} \mathrm{al.} \mathrm{Lushan} M_{\mathrm{S}} 7.0$ earthquake: A blind reserve-fault earthquake. Chin Sci Bull, 2013, 58: 3437-3443

13 Wang E, Meng Q. Mesozoic and Cenozoic tectonic evolution of the Longmenshan fault belt. Sci China Ser D-Earth Sci, 2009, 52: 579592

14 Yang X P, Jiang B, Song F M, et al. The evidence of the south Longmenshan fault cutting late quaternary stratum (in Chinese). Seismol Geol, 1999, 21: 341-345

$15 \mathrm{Xu}$ Z Q, Li H Q, Hou L W, et al. Uplift of the Longmen-Jinping orogenic belt along the eastern margin of the Qinghai-Tibtet Plateau: Large-scale detachment faulting and extrusion mechanism. Geol Bull Chin, 2007, 26: 1262-1276

16 Zhao G, Chen X, Wang L, et al. Evidence of crustal 'channel flow' in eastern margin of Tibet Plateau from MT measurements. Chin Sci Bull, 2008, 53: 1887-1893

17 Zhao G Z, Martyn J U, Yan Z, et al. Crustal structure and rheology of the Longmenshan and Wenchuan $M_{\mathrm{W}} 7.9$ earthquake epicentral area from magnetotelluric data. Geology, 2012, 40: 1139- 1142

18 Tapponnier P, Peltzer G, Armijo R. On the mechanics of the collision between India and Asia. Geol Soc Lond, 1986, 19: 113-157

19 Deng Q, Zhang P Z, Ran Y K, et al. Basic characteristics of active tectonics of China. Sci China Ser D-Earth Sci, 2003, 46: 356-372

20 Roger F, Malavieille J, Leloup $\mathrm{Ph} \mathrm{H}$, et al. Timing of granite emplacement and cooling in the Songpan-Garzê Fold Belt (eastern Tibetan Plateau) with tectonic implications. J Asian Earth Sci, 2004, 22: 465-481

21 Wen X, Yi G. Re-zoning of statistic units of seismicity in SichuanYunnan region. J Seismol Res, 2003, 26: 1-9

22 Wang Y Z, Wang E N, Shen Z K. GPS-constrained inversion of present-day slip rates along major faults of the Sichuan-Yunnan region China. Sci China Ser D-Earth Sci, 2008, 38: 582-597

23 Zhu A, Xu X, Diao G L, et al. Relocation of the $M_{\mathrm{W}} 8.0$ Wenchuan earthquake sequence in part: Preliminary seismotectonic analysis (in Chinese). Seismol Geol, 2008, 30: 759-767

24 Fan L H, Wu J P, Wang W L, et al. Relocation of main shock and aftershoke sequences of $M_{\mathrm{S}} 7.0$ Sichuan Lushan earthquake. Chin Sci Bull, 2013, 58: 3451-3459

25 Cai J T, Chen X B, Zhao G Z. Refined techniques for data processing and two-dimensional inversion in magnetotelleric 1: Tensor decomposition and dimensionality analysis (in Chinese). Chin J Geophys, 2010, 53: 516-526

26 Caldwell G T, Bibby M H, Brown C. The magnetotelluric phase tensor. Geophys J Inter, 2004, 158: 457-469

27 Booker J R. Magnetotellutic phase tensor evolution. 21st Electromagnetic (EM) Induction Workshop, Darwin, Australia, 2012

28 Rodi W, Mackie R L. Nonlinear conjugate gradients algorithm for 2-D magnetotelluric inversion. Geophysics, 2001, 66: 174-187

29 Chen X B, Zhao G Z, Tang J, et al. Magnetotelluric adaptive regularized uoze algorithm (in Chinese). Chin J Geophys, 2005, 48: 937-946

30 Xiao Q, Zhao G, Dong Z. Electrical resistivity structure at the northern margin of the Tibetan Plateau and tectonic implications. J Geophys Res, 2011, 116: 1-14

31 Yu G H, Xu X W, Klinger Y, et al. Fault-scarp features and cascading-rupture model for the Wenchuan earthquake $\left(M_{\mathrm{W}} 7.9\right)$, eastern Tibetan Plateau, China. Bull Seismol Soc Am, 2010, 100: 2590-2614

32 Zhang Y, Xu L S, Chen Y T. Lushan 4. 20 hazard characteristics of earthquake rupture process and its preliminary analysis (in Chinese). Chin J Geophys, 2013, 56: 1408-1411

33 Wang W M, Han K M, Yao Z X. 2013 year April 20 Sichuan earthquake rupture process inversion Lushan preliminary results (in Chinese). Chin J Geophys, 2013, 56: 1412-1417

34 Zeng X F, Luo Y, Han L B, et al. April 20, 2013 earthquake in Si- 
chuan Lushan $M_{\mathrm{S}}$ 7. 0: A high-angle thrust earthquakes (in Chinese). Chin J Geophys, 2013, 56: 1418-1420

35 Royden L H, Burchfiel B C, Robert W, et al. Surface deformation and lower crustal flow in eastern Tibet. Science, 1997, 276: 788-790

36 Clark M K, Royden L H. Topographic ooze: Building the eastern margin of Tibet by lower crustal flow. Geology, 2000, 28: 703-706

37 Wei W, Unsworth M J, Jones A G, et al. Detection of wide spread fluids in the Tibetan crust by magnetotelluric studies. Science, 2001, 292: 716-718

38 Unsworth M J, Jones A G, Wei W, et al. Crustal rheology of the Himalaya and Southern Tibet inferred from magnetotelluric data. Nature, 2005, 433: 78-81

39 Zhang Z J, Wang Y H, Chen Y, et al. Crustal structure across Longmenshan fault belt from passive source seismic profiling. Geophys Res Lett, 2010, 292: 254-264

40 Bai D, Unsworth J M, Meju A M, et al. Crustal deformation of the eastern Tibetan Plateau revealed by magnetotelluric imaging. Nat Geosci, 2010, 3: 358-362

41 Robert A, Pubellier M, Sigoyer J, et al. Structural and thermal characters of the Longmen Shan (Sichuan, China). Tectonophyics, 2010, 491: $165-173$

42 Zhao G Z, Tang J, Zhan Y, et al. Relation between electricity structure of the crust and deformation of crustal blocks on the northeastern margin of Qinghai-Tibet Plateau. Sci China Ser D-Earth Sci, 2005, 48: $1613-1626$

43 Wang X B, Zhu Y T, Zhao X K, et al. Deep conductivity characteristics of the Longmen Shan, Eastern Qinghai-Tibet Plateau (in Chinese). Chin J Geophys, 2009, 52: 564-571

44 Duvall A R, Clark M K. Dissipation of fast strike-slip faulting within and beyond northeastern Tibet. Geology, 2010, 38: 223-226

45 Zhang P Z. Beware of slowly slipping faults. Nat Geosci, 2013, 6: $323-324$

Open Access This article is distributed under the terms of the Creative Commons Attribution License which permits any use, distribution, and reproduction in any medium, provided the original author(s) and source are credited. 